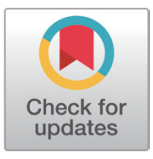

Received: Aug 27, 2020

Revised: Sep 8, 2020

Accepted: Sep 10, 2020

*Corresponding author Jong Youn Jeong

School of Food Biotechnology \&

Nutrition, Kyungsung University, Busan

48434 , Korea.

Tel: +82-51-663-4711

E-mail: jeongjy@ks.ac.kr

Copyright () 2020 Korean Society of Animal Sciences and Technology.

This is an Open Access article distributed under the terms of the Creative Commons Attribution

Non-Commercial License (http:// creativecommons.org/licenses/by$\mathrm{nc} / 4.0 /$ ) which permits unrestricted non-commercial use, distribution, and reproduction in any medium, provided the original work is properly cited.

ORCID

Su Min Bae

https://orcid.org/0000-0002-9367-4594 Jae Hyeong Choi

https://orcid.org/0000-0002-9158-2418

Jong Youn Jeong

https://orcid.org/0000-0001-5284-4510

Competing interests

No potential conflict of interest relevant to this article was reported.

Funding sources

This work was supported by Korea Institute of Planning and Evaluation for Technology in Food, Agriculture and Forestry (IPET) through Innovational Food Product and Natural Food

Materials Development Program,

\section{Effects of radish powder concentration and incubation time on the physicochemical characteristics of alternatively cured pork products}

\author{
Su Min Bae, Jae Hyeong Choi and Jong Youn Jeong* \\ School of Food Biotechnology \& Nutrition, Kyungsung University, Busan 48434, Korea
}

\section{Abstract}

Previous research has indicated that radish powder could be a suitable replacement for chemical nitrite sources in alternatively cured meat products. However, the effects of radish powder level on the physicochemical properties of cured meat have not been systematically studied. In this study, we aimed to investigate the effects of varying concentrations of radish powder and incubation time on the physicochemical properties and cured meat pigments of alternatively cured meat products. We divided our experimental setup into seven groups with different radish powder concentrations and incubation times: control ( $0.01 \%$ sodium nitrite), treatment $1(0.15 \%$ radish powder and $2 \mathrm{~h}$ incubation), treatment $2(0.15 \%$ radish powder and $4 \mathrm{~h}$ incubation), treatment $3(0.30 \%$ radish powder and $2 \mathrm{~h}$ incubation), treatment $4(0.30 \%$ radish powder and $4 \mathrm{~h}$ incubation), treatment $5(0.30 \%$ celery powder and $2 \mathrm{~h}$ incubation), and treatment $6\left(0.30 \%\right.$ celery powder and $4 \mathrm{~h}$ incubation). The cooking yield, $\mathrm{ClE} \mathrm{a}^{*}$ values (redness), and total pigment levels were not significantly different $(p>0.05)$ between any of the alternatively cured treatments and the control. However, when $0.30 \%$ radish powder or celery powder was added to the products, the CIE $b^{*}$ values increased significantly $(p<0.05)$ with incubation time. At the same vegetable concentration, the nitrite content, nitrosyl hemochrome, and curing efficiency also increased significantly $(p<0.05)$ as the incubation time increased from 2 to $4 \mathrm{~h}$, regardless of the types of vegetable powder. Among the meat products cured with radish powder, treatment 4 showed the highest increase in residual nitrite content, nitrosyl hemochrome content, and curing efficiency, but showed decreased lipid oxidation. Our results suggest that increased concentrations of radish powder and longer incubation times would be more suitable for producing alternatively cured meat products comparable to traditionally cured products treated with synthetic nitrite.

Keywords: Radish powder, Incubation time, Nitrite replacement, Alternatively cured meat products 
funded by Ministry of Agriculture, Food and Rural Affairs (MAFRA) (119028-03-2HD040), and the BB21+ Project in 2020.

Acknowledgements Not applicable.

Availability of data and material Upon reasonable request, the datasets of this study can be available from the corresponding author.

Authors' contributions

Conceptualization: Jeong JY.

Data curation: Bae SM.

Formal Analysis: Bae SM, Choi JH.

Methodology: Bae SM, Choi JH.

Software: Bae SM, Choi JH.

Validation: Bae SM, Choi JH, Jeong JY. Investigation: Bae SM, Choi JH, Jeong JY. Writing - original draft: Bae SM, Choi JH. Writing - review \& editing: Bae SM, Choi JH, Jeong JY.

Ethics approval and consent to participate This article does not require IRB/IACUC approval because there are no human and animal participants.

\section{INTRODUCTION}

Nitrite is used in the curing of various meat products to improve flavor and color and to prevent lipid oxidation [1-3]. Nitrite also helps control contamination by anaerobic bacteria, especially Clostridium botulinum, and it suppresses other microorganisms such as Listeria monocytogenes [1,4]. Despite these benefits, nitrite-treated meat products attract negative consumer perception due to the potential for the formation of nitrosamines [5]. Therefore, researchers have long been attempting to identify suitable replacements for nitrite in meat curing [6-11]. Although no alternatives have been found to completely replace synthetic nitrite, some vegetables that contain considerable amounts of nitrate are used today as natural replacements for nitrite/nitrate in alternatively cured processed meat or naturally cured processed meat $[4,12]$. In previous studies, celery, parsley, Swiss chard, spinach, and cabbage have been found to be suitable natural replacements for synthetic nitrite [10,13-16].

Radish has high nitrate contents ranging from 1,878 to $6,260 \mathrm{ppm}[12,17,18]$. It also contains bioactive compounds such as ascorbic acid, polyphenols, and flavonoids [19]. Furthermore, as radish roots are usually white in color $[19,20]$, its effect on the color of the final meat product is expected to be less drastic than that of other leafy vegetables. Thus, radish powder may be a useful natural replacement for synthetic nitrite in alternatively cured meat products. However, thus far, there have been no studies on the effects of different concentrations of radish powder on cured meat products.

To generate nitrite from the natural nitrate in vegetables such as radish, specific microorganisms that produce nitrate reductases are required; Staphylococcus carnosus and S. xylosus are examples of such microbes, among others [1]. Optimal temperature and incubation time are necessary to allow the conversion of nitrate to nitrite by these bacteria, prior to thermal processing of the meat products. The importance of incubation time for the proper development of desirable cured meat characteristics has been shown in previous studies [10,11,21]. Sindelar et al. [11] reported that a longer incubation time (120 min instead of $30 \mathrm{~min}$ ) was more critical than a higher concentration of vegetable powders $(0.20 \%$ or $0.40 \%)$ for the production of indirectly cured sausages comparable to sodium nitrite-treated ones. Terns et al. [21] also found that increasing the incubation time was more important for improving the properties of cured meat than increasing the amount of starter culture used $(0.01 \%$ or $0.02 \%)$. However, indirectly cured meat products incubated for less than 2 hours show lower residual nitrite levels than sodium nitrite-treated controls [11,14,22]. It is possible that longer incubation times are required to produce sufficient nitrite to achieve the desired levels of cured meat color characteristics in alternatively cured products. However, so far, there have not been any systematic studies on the combined effects of longer incubation time at different concentrations of vegetable powders on the quality of alternatively cured meat products. In this study, we investigated the effects of different concentrations of radish powder and incubation times on the physicochemical properties and cured meat pigments of alternatively cured meat products, by comparing with products with sodium nitrite or commercially available celery powders.

\section{MATERIALS AND METHODS}

\section{The preparation of radish powder}

To manufacture radish powder with high concentrations of nitrate, radishes were purchased from five provinces of Korea (Chungcheong-do, Gangwon-do, Gyeonggi-do, Gyeongsangdo, and Jeolla-do) and randomly selected (approximately $10 \mathrm{~kg} /$ region) for the experiment. The selected radish roots were cut into cubes of approximately $2 \times 3 \times 3 \mathrm{~cm}^{3}$ after washing, peeling, and removing the inedible portions. These radish cubes were blended using a food cutter $(\mathrm{C} 6 \mathrm{VV}$, 
Sirman, Marsango, Italy) for $6 \mathrm{~min}$, vacuum-packed in nylon/polyethylene bags ( $500 \mathrm{~g}$ each), and stored in a freezer (C110AHB, LG Electronics, Changwon, Korea) at $-24^{\circ} \mathrm{C}$ prior to hot air drying. Before drying, the nitrate and nitrite ion contents in the homogenized radish were measured. The frozen radishes were placed on a Teflon sheet (TBS-345, Alphaflon, Seoul, Korea) and dried at $60^{\circ} \mathrm{C}$ for 12 hours in a food dryer (EN-FO-392S, Enex Science, Goyang, Korea). The dried radishes were then pulverized with a blender (51BL30, Waring Commercial, Torrington, CT, USA) for 3 min and filtered through a 30-mesh sieve (Test sieve BS0600, Chunggye Sieve, Gunpo, Korea). The resulting radish powder was vacuum-packed and stored at $-24^{\circ} \mathrm{C}$ until use. The nitrate and nitrite ion content and $\mathrm{pH}$ of the radish powder were measured prior to the meat processing.

\section{The preparation of raw materials and processing of cured meat products}

Fresh pork ham (M. biceps femoris, $M$. semitendinosus, and M. semimembranosus) and backfat were purchased from a local meat processor (Pukyung Pig Farmers Livestock, Kimhae, Korea) at 24-48 hours postmortem. After removing the intermuscular fat and visible connective tissues from the pork ham, the lean pork meat and backfat were sequentially ground using a chopper (TC-22 Elegant plus, Tre Spade, Torino, Italy) with an 8-mm and a 3-mm plate, respectively. Celery powder (VegStable 502, Florida Food Products, Eustis, FL, USA) with a nitrate ion content of 23,375 ppm (equivalent to 32,020 ppm sodium nitrate), a starter culture (CS 299, CHR Hansen, Milwaukee, WI, USA) of Staphylococcus carnosus, sodium nitrite (S2252, Sigma-Aldrich, St. Louis, MO, USA), and sodium ascorbate (\#35268, Acros Organics, Geel, Belgium) were obtained from commercial suppliers.

Ground pork meat and fat (total batches of $30 \mathrm{~kg}$ per trial) were randomly assigned to the control group and six treatment groups (Table 1): control group, $0.01 \%$ sodium nitrite; treatment $1,0.15 \%$ radish powder and 2 hours incubation; treatment $2,0.15 \%$ radish powder and 4 hours

Table 1. The formulation for alternatively cured meat products formulated with different types and concentrations of vegetable powders

\begin{tabular}{|c|c|c|c|c|}
\hline Ingredients (\%) & Control $^{1)}$ & Treatments 1 and 2 & Treatments 3 and 4 & Treatments 5 and 6 \\
\hline Pork ham & 70.00 & 70.00 & 70.00 & 70.00 \\
\hline Pork backfat & 15.00 & 15.00 & 15.00 & 15.00 \\
\hline Ice/water & 15.00 & 15.00 & 15.00 & 15.00 \\
\hline Sub total & 100.00 & 100.00 & 100.00 & 100.00 \\
\hline $\mathrm{NaCl}$ & 1.50 & 1.50 & 1.50 & 1.50 \\
\hline Sugar & 1.00 & 1.00 & 1.00 & 1.00 \\
\hline Sodium tripolyphosphate & 0.30 & 0.30 & 0.30 & 0.30 \\
\hline Sodium ascorbate & 0.05 & 0.05 & 0.05 & 0.05 \\
\hline Mustard powder & 0.30 & 0.30 & 0.30 & 0.30 \\
\hline Black pepper & 0.25 & 0.25 & 0.25 & 0.25 \\
\hline Monosodium glutamate & 0.10 & 0.10 & 0.10 & 0.10 \\
\hline Onion powder & 0.10 & 0.10 & 0.10 & 0.10 \\
\hline Garlic powder & 0.10 & 0.10 & 0.10 & 0.10 \\
\hline Sodium nitrite & 0.01 & 0.00 & 0.00 & 0.00 \\
\hline Radish powder & 0.00 & 0.15 & 0.30 & 0.00 \\
\hline Celery powder & 0.00 & 0.00 & 0.00 & 0.30 \\
\hline Starter culture & 0.00 & 0.015 & 0.03 & 0.03 \\
\hline Total & 103.71 & 103.865 & 104.03 & 104.03 \\
\hline
\end{tabular}

${ }^{1)}$ Control, $0.01 \%$ sodium nitrite; Treatment 1, 0.15\% radish powder and 2 hours incubation; Treatment 2, 0.15\% radish powder and 4 hours incubation; Treatment 3, 0.30\% radish powder and 2 hours incubation; Treatment 4, 0.30\% radish powder and 4 hours incubation; Treatment $5,0.30 \%$ celery powder and 2 hours incubation; Treatment $6,0.30 \%$ celery powder and 4 hours incubation. 
incubation; treatment 3, 0.30\% radish powder and 2 hours incubation; treatment $4,0.30 \%$ radish powder and 4 hours incubation; treatment 5, 0.30\% celery powder and 2 hours incubation; and treatment $6,0.30 \%$ celery powder and 4 hours incubation. In the alternatively cured treatments, the starter culture was added at a concentration of $10 \%$ of the amount of radish powder or celery powder added. The ground pork meat and backfat were mixed with $\mathrm{NaCl}$, sodium tripolyphosphate, vegetable powders or sodium nitrite (depending on treatments), other ingredients, and ice/water using a mixer (5K5SS, Whirlpool, St. Joseph, MI, USA) for $10 \mathrm{~min}$. The mixtures from each batch were stuffed into conical tubes (approximately $50 \mathrm{~g}$ each), which were then centrifuged at 2,000 $\mathrm{xg}$ for 10 min (Combi R515, Hanil Science Industrial, Incheon, Korea) to remove air pockets. The controls were placed in a refrigerator at $2{ }^{\circ} \mathrm{C}-3^{\circ} \mathrm{C}$ for 1 hour and the treatment groups were kept in an incubator (C-IB4, Changshin Science, Pocheon, Korea) at $38^{\circ} \mathrm{C}$ for 2 hours or 4 hours, depending on the treatment group. The tubes were then cooked to reach an internal temperature of $75^{\circ} \mathrm{C}$ in a water bath (MaXturdy 45 , Daihan Scientific, Wonju, Korea) at $90^{\circ} \mathrm{C}$ set. The cooked samples were immediately cooled for $20 \mathrm{~min}$ on slurry ice and stored at $2{ }^{\circ} \mathrm{C}-3^{\circ} \mathrm{C}$ in the dark until analysis. All experiments were performed in triplicate.

The $\mathrm{pH}$ measurement

A pH meter (Accumet AB150, Thermo Fisher Scientific, Waltham, MA, USA) was used to measure the $\mathrm{pH}$ on five grams of the fresh radish, the radish powder, and the cooked meat samples homogenized in $45 \mathrm{~mL}$ of distilled water.

\section{Cooking yield determination}

Each meat sample in the conical tube was weighed before cooking, and then weighed again after cooking and cooling. The cooking yield was determined using the equation:

$$
\text { Cooking yield }(\%)=\frac{\text { Sample weight after cooking }}{\text { Sample weight before cooking }} \times 100
$$

\section{CIE color measurement}

The Commission Internationale de l'Eclairage (CIE) L* (lightness), a* (redness), and b* (yellowness) values were measured on the freshly cut surfaces of each cooked sample using a colorimeter (Chroma Meter CR-400, illuminant C, $2^{\circ}$ standard observer; Konica Minolta Sensing, Osaka, Japan) calibrated with a white plate ( $\left.\mathrm{L}^{*} 94.90, \mathrm{a}^{*}-0.39, \mathrm{~b}^{*} 3.88\right)$.

\section{Nitrate and nitrite ion content measurement for fresh radish and powder}

The nitrate $\left(\mathrm{NO}_{3}^{-}\right)$and nitrite $\left(\mathrm{NO}_{2}^{-}\right)$ion contents in the homogenized radish and prepared radish powder were determined using the zinc reduction method described by Merino [23]. The observed results were converted in terms of the concentration of sodium nitrite and expressed as ppm.

\section{Residual nitrite content analysis for cured meat products}

The residual nitrite content in the cooked meat samples was determined by the AOAC method [24]. The results were reported as ppm by a standard curve using sodium nitrite (S2252, SigmaAldrich).

\section{Nitrosyl hemochrome, total pigment and curing efficiency analysis}

Nitrosyl hemochrome and total pigment content in the cooked cured products were determined 
after extraction in $80 \%$ acetone and acidified acetone using a method established by Hornsey [25]. The nitrosyl hemochrome concentration (ppm) was calculated as $A_{540} \times 290$. The total pigment concentration $(\mathrm{ppm})$ was calculated as $\mathrm{A}_{640} \times 680$. Finally, curing efficiency (\%) was calculated using the equation:

$$
\text { Curing efficiency }(\%)=\frac{\text { Nitrosyl hemochrome content }}{\text { Total pigment content }} \times 100
$$

\section{Determination of thiobarbituric acid reactive substances (TBARS)}

Malondialdehyde (MDA) content was measured based on 2-thiobarbituric acid reactive substances (TBARS) values using a distillation method reported by Tarladgis et al. [26]. The TBARS values were reported as milligrams of MDA per kilogram of the cooked samples (mg MDA/kg).

\section{Statistical analysis}

All experiments were performed in triplicate. The experimental design was a randomized block design with seven groups (one control group and six treatment groups). Data were statistically analyzed using the Proc GLM (general linear model) in the SAS program (Statistical Analysis System 2012, version 9.4, SAS Institute, Cary, NC, USA). If the model revealed a significant difference $(p<0.05)$, the significance of the means was further separated using Tukey's multiple comparison test.

\section{RESULTS AND DISCUSSION}

\section{Nitrate content, nitrite content, and $\mathrm{pH}$ of radish and radish powder}

The ground raw radish had 2,619 ppm nitrate ion and $0.06 \mathrm{ppm}$ nitrite ion (Table 2). The nitrate and nitrite ion content in radishes varied between regions, and this may be attributed to variations in cultivar type, environmental factors, and fertilizers [12,27]. Chung et al. [17] reported that radish from Korea contained 1,878 ppm nitrate ion and $0.80 \mathrm{ppm}$ nitrite ion, which were lower than the values we obtained. Raczuk et al. [18] found that radishes from Poland had, on average, 2,132 ppm nitrate ion and $1.90 \mathrm{ppm}$ nitrite ion. After hot air drying, the radish powder had 55,935 ppm nitrate ion (equivalent to $76,623 \mathrm{ppm}$ sodium nitrate) and $0.09 \mathrm{ppm}$ nitrite ion (equivalent to 0.14 ppm sodium nitrite) (Table 2). This increase in nitrate and nitrite ion contents could be attributed to the evaporation of moisture due to the drying process $[14,22,28]$.

Commercially available celery powder or juice powder typically contains about 30,000 ppm nitrate [2]. Our results indicated that the radish powder we prepared could have sufficient nitrate content for use in the production of alternatively cured meat products. The radish and radish powder had a $\mathrm{pH}$ of 5.92 and 5.09, respectively (Table 2). Similarly, Jeong et al. [14] found that dried powder prepared from radish grown in the Jeolla-do region of Korea had a $\mathrm{pH}$ of 5.14.

\section{Physicochemical properties of alternatively cured pork products}

The cooking yield ranged from $99.43 \%$ to $99.53 \%$ and was not affected $(p>0.05)$ by the incubation time or the concentration of radish powder or celery powder added (Table 3). These results were consistent with those of Banerjee et al. [29], who found that nuggets treated with different concentrations of broccoli powder showed no difference in cooking yield. However, our results disagree with those of Choi et al. [6], who reported that naturally cured products treated with white kimchi powder and celery powder had lower cooking yields than sodium nitrite-treated controls. 
Table 2. The nitrate ion content, sodium nitrate content, nitrite ion content, sodium nitrite content, and pH in radish and radish powder

\begin{tabular}{lcc}
\hline \multicolumn{1}{c}{ Traits } & Raw radish & Radish powder \\
\hline Nitrate ion content $\left(\mathrm{NO}_{3}{ }^{-}, \mathrm{ppm}\right)$ & $2,619 \pm 52.28$ & $55,935 \pm 2,456$ \\
Sodium nitrate content $\left(\mathrm{NaNO}_{3}, \mathrm{ppm}\right)$ & $3,588 \pm 71.62$ & $76,623 \pm 3,365$ \\
Nitrite ion content $\left(\mathrm{NO}_{2}^{-}, \mathrm{ppm}\right)$ & $0.06 \pm 0.04$ & $0.09 \pm 0.03$ \\
Sodium nitrite content $\left(\mathrm{NaNO}_{2}, \mathrm{ppm}\right)$ & $0.09 \pm 0.04$ & $0.14 \pm 0.05$ \\
$\mathrm{pH}$ & $5.92 \pm 0.05$ & $5.09 \pm 0.99$ \\
\hline
\end{tabular}

Table 3. Effects of radish powder on cooking yield, $\mathrm{pH}$ values, and CIE color values of alternatively cured meat products

\begin{tabular}{lccccc}
\hline \multicolumn{1}{c}{ Treatments $^{1)}$} & Cooking yield (\%) & pH & CIE L* $^{*}$ & CIE a $^{*}$ & $8.05 \pm 0.09^{\mathrm{C}}$ \\
\hline Control & $99.50 \pm 0.04$ & $6.10 \pm 0.01^{\mathrm{D}}$ & $66.32 \pm 0.17^{\mathrm{B}}$ & $8.55 \pm 0.10$ & $7.90 \pm 0.06^{\mathrm{C}}$ \\
Treatment 1 & $99.53 \pm 0.04$ & $6.18 \pm 0.01^{\mathrm{A}}$ & $67.25 \pm 0.20^{\mathrm{A}}$ & $8.31 \pm 0.10$ & $8.08 \pm 0.07^{\mathrm{C}}$ \\
Treatment 2 & $99.40 \pm 0.02$ & $6.19 \pm 0.01^{\mathrm{A}}$ & $66.83 \pm 0.11^{\mathrm{AB}}$ & $8.44 \pm 0.12$ & $7.97 \pm 0.11^{\mathrm{C}}$ \\
Treatment 3 & $99.47 \pm 0.02$ & $6.14 \pm 0.01^{\mathrm{BC}}$ & $67.03 \pm 0.23^{\mathrm{A}}$ & $8.44 \pm 0.21$ & $8.36 \pm 0.07^{\mathrm{B}}$ \\
Treatment 4 & $99.43 \pm 0.01$ & $6.15 \pm 0.01^{\mathrm{B}}$ & $67.03 \pm 0.16^{\mathrm{AB}}$ & $8.42 \pm 0.09$ & $8.37 \pm 0.10^{\mathrm{B}}$ \\
Treatment 5 & $99.53 \pm 0.02$ & $6.13 \pm 0.01^{\mathrm{BC}}$ & $67.18 \pm 0.16^{\mathrm{A}}$ & $8.30 \pm 0.06$ & $8.66 \pm 0.08^{\mathrm{A}}$ \\
Treatment 6 & $99.45 \pm 0.01$ & $6.12 \pm 0.01^{\mathrm{CD}}$ & $66.74 \pm 0.19^{\mathrm{AB}}$ & $8.47 \pm 0.14$ & \\
\hline
\end{tabular}

All values are means \pm SE

Number of observations in the treatments, $\mathrm{n}=15$ (cooking yield); $6(\mathrm{pH}) ; 12(\mathrm{ClE} \mathrm{L*}) ; 12\left(\mathrm{CIE} \mathrm{a}^{*}\right) ; 12(\mathrm{CIE} \mathrm{b*).}$

${ }^{1)}$ Control, $0.01 \%$ sodium nitrite; Treatment $1,0.15 \%$ radish powder and 2 hours incubation; Treatment $2,0.15 \%$ radish powder and 4 hours incubation; Treatment $3,0.30 \%$ radish powder and 2 hours incubation; Treatment $4,0.30 \%$ radish powder and 4 hours incubation; Treatment $5,0.30 \%$ celery powder and 2 hours incubation; Treatment $6,0.30 \%$ celery powder and 4 hours incubation.

${ }^{A-D}$ Mean within a column with different superscript letters are significantly different $(p<0.05)$.

This difference in results could be attributed to the difference in phosphate levels in the products. Unlike in our study, Choi et al. [6] did not include phosphate in their product formulation. Regarding the incubation time, our results are consistent with those of Sindelar et al. [30], who reported that incubation time did not affect the cooking yield in indirectly cured jerkies.

All alternatively cured pork products had significantly higher $(p<0.05) \mathrm{pH}$ than the controls, except for treatment 6 ( $0.30 \%$ celery powder and 4 hours incubation time) (Table 3$)$. Jeong et al. [14] reported similar results; they found that cured pork products treated with Chinese cabbage, radish, or spinach powder showed higher $\mathrm{pH}$ than nitrite-added controls. In our study, products treated with $0.15 \%$ radish powder (treatments 1 and 2 ) had higher $\mathrm{pH}$ than those treated with $0.30 \%$ radish powder (treatments 3 and 4 ) or $0.30 \%$ celery powder (treatments 5 and 6), suggesting that the $\mathrm{pH}$ in alternatively cured products decreased as the concentration of vegetable powders increased. However, the incubation time did not affect the $\mathrm{pH}$ of the alternatively cured products, irrespective of the concentration of the vegetable powders.

The CIE L* (lightness), $a^{*}$ (redness), and $b^{*}$ (yellowness) values of alternatively cured meat products in this study are shown in Table 3. There were no differences $(p>0.05)$ in CIE $L^{*}$ values between the naturally cured pork products, suggesting that the types and levels of vegetable powder added and the incubation time did not affect $(p>0.05)$ CIE L* values. However, cured products incubated for 2 hours (treatments 1, 3, and 5) had CIE L* values higher $(p<0.05)$ than those of the control, while treatments 2,4 , and 6, which were incubated for 4 hours, had similar CIE L* values as the control. These results are consistent with those of Sindelar et al. [11], who found that the CIE L* values of emulsified cooked sausages were not affected by the concentration of the vegetable juice powder $(0.2 \%$ or $0.4 \%$ ) or the incubation time (30 $\mathrm{min}$ or $120 \mathrm{~min}$ ). In this study, CIE $a^{*}$ values ranged from 8.30 to 8.55 , with no significant differences $(p>0.05)$ between the control and the treatments. Interestingly, despite the difference in concentration of added vegetable 
powder, cured pork products with $0.15 \%$ radish powder (treatments 1 and 2 ) and those with $0.30 \%$ radish or celery powder (treatments 3-6) had similar redness. Similar results were reported by Choi et al. [6], who found that using different concentrations ( $0.2 \%$ and $0.4 \%)$ of white kimchi powder in combination with a nitrate-reducing starter culture and incubating for 2 hours resulted in similar CIE $a^{*}$ values in alternatively cured meat products. Furthermore, the incubation time ( 2 hours and 4 hours) did not affect the CIE $\mathrm{a}^{*}$ values of the alternatively cured pork products in our study, regardless of the concentration of the vegetable powders. These results indicate that the use of radish powder, along with a short incubation time of 2 hours could produce a redness in alternatively cured meat products comparable to that in traditionally cured products and those treated with commercially available celery powders. $\mathrm{CIE} b^{*}$ values of cured products treated with celery powder (treatments 5 and 6 ) were higher $(p<0.05)$ than the control, but no differences $(p>$ $0.05)$ in CIE $b^{*}$ values were observed between the control and other treatments, except treatment 4. These results were consistent with those of Jeong et al. [14], who reported that when cured pork products were treated with different vegetable powders and a starter culture, followed by incubating for 2 hours, the yellowness of the final products were increased after treatment with Chinese cabbage or spinach powder, but those treated with radish powder had similar CIE $b^{*}$ values to the nitrite-added control. Furthermore, Krause et al. [31] reported that uncured sliced ham treated with vegetable juice powder and a starter culture showed higher $b^{*}$ values than the sodium nitritetreated control, which is consistent with our results for the celery powder treatments. The increased yellowness in the products treated with celery powder may be attributed to the presence of yellow pigments like carotenoids in celery [32]. We also observed that the incubation time did not affect

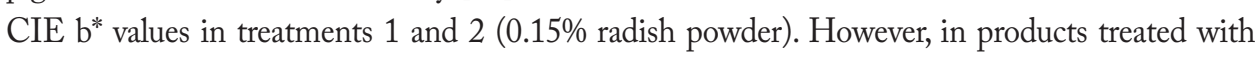
$0.3 \%$ radish powder and $0.3 \%$ celery powder, the $\mathrm{CIE}^{*}$ * values increased $(p<0.05)$ with incubation time, which was consistent with the observations of Kim et al. [13] in cured pork loins incubated with spinach and a starter culture.

The products treated with $0.30 \%$ radish powder (treatment 4 ) were found to have higher $(p<$ 0.05 ) residual nitrite contents than those treated with $0.15 \%$ radish powder (treatment 2 ) (Table 4). Interestingly, treatment 4 ( $0.30 \%$ radish powder) resulted in a higher residual nitrite content than treatment $6(0.30 \%$ celery powder $)$, which may be attributed to the relatively high nitrate content of radish powder prepared for our study. Thus, among the vegetable powder treatments, treatment

Table 4. Effects of radish powder on residual nitrite, nitrosyl hemochrome, total pigments, curing efficiency, and TBARS of alternatively cured meat products

\begin{tabular}{lccccc}
\hline \multicolumn{1}{c}{ Treatments $^{1)}$} & $\begin{array}{c}\text { Residual nitrite } \\
(\mathbf{p p m})\end{array}$ & $\begin{array}{c}\text { Nitrosyl hemochrome } \\
(\mathbf{p p m})\end{array}$ & $\begin{array}{c}\text { Total pigment } \\
(\mathbf{p p m})\end{array}$ & $\begin{array}{c}\text { Curing efficiency } \\
(\%)\end{array}$ & $\begin{array}{c}\text { TBARS } \\
(\mathbf{m g} \text { MAD/kg) }\end{array}$ \\
\hline Control & $41.56 \pm 1.12^{\mathrm{A}}$ & $34.80 \pm 0.21^{\mathrm{AB}}$ & $46.58 \pm 0.29$ & $74.71 \pm 0.13^{\mathrm{B}}$ & $0.088 \pm 0.005^{\mathrm{B}}$ \\
Treatment 1 & $7.04 \pm 0.88^{\mathrm{E}}$ & $31.47 \pm 0.36^{\mathrm{D}}$ & $45.73 \pm 0.21$ & $68.79 \pm 0.52^{\mathrm{D}}$ & $0.138 \pm 0.006^{\mathrm{A}}$ \\
Treatment 2 & $18.14 \pm 0.27^{\mathrm{C}}$ & $34.29 \pm 0.12^{\mathrm{BC}}$ & $45.90 \pm 0.13$ & $74.72 \pm 0.37^{\mathrm{B}}$ & $0.121 \pm 0.006^{\mathrm{A}}$ \\
Treatment 3 & $9.19 \pm 0.27^{\mathrm{DE}}$ & $33.42 \pm 0.57^{\mathrm{C}}$ & $45.73 \pm 0.33$ & $73.05 \pm 0.72^{\mathrm{C}}$ & $0.119 \pm 0.008^{\mathrm{A}}$ \\
Treatment 4 & $39.62 \pm 1.34^{\mathrm{A}}$ & $35.53 \pm 0.12^{\mathrm{AB}}$ & $45.90 \pm 0.28$ & $77.41 \pm 0.38^{\mathrm{A}}$ & $0.080 \pm 0.004^{\mathrm{B}}$ \\
Treatment 5 & $10.95 \pm 0.78^{\mathrm{D}}$ & $33.42 \pm 0.22^{\mathrm{C}}$ & $46.07 \pm 0.33$ & $72.55 \pm 0.14^{\mathrm{C}}$ & $0.125 \pm 0.006^{\mathrm{A}}$ \\
Treatment 6 & $21.99 \pm 0.24^{\mathrm{B}}$ & $35.82 \pm 0.05^{\mathrm{A}}$ & $46.07 \pm 0.28$ & $77.76 \pm 0.46^{\mathrm{A}}$ & $0.092 \pm 0.007^{\mathrm{B}}$ \\
\hline
\end{tabular}

All values are means $\pm \mathrm{SE}$.

Number of observations in the treatments, $\mathrm{n}=12$ (residual nitrite); 12 (nitrosyl hemochrome); 12 (total pigment); 12 (curing efficiency); 12 (TBARS).

${ }^{1)}$ Control, $0.01 \%$ sodium nitrite; Treatment $1,0.15 \%$ radish powder and 2 hours incubation; Treatment 2: $0.15 \%$ radish powder and 4 hours incubation; Treatment $3,0.30 \%$ radish powder and 2 hours incubation; Treatment $4,0.30 \%$ radish powder and 4 hours incubation; Treatment $5,0.30 \%$ celery powder and 2 hours incubation; Treatment $6,0.30 \%$ celery powder and 4 hours incubation.

${ }^{A-E}$ Mean within a column with different superscript letters are significantly different $(p<0.05)$.

TBARS, 2-Thiobarbituric acid reactive substances. 
4 had the highest $(p<0.05)$ residual nitrite content, which was not different $(p>0.05)$ from that of the sodium nitrite-treated control. When alternatively cured products were incubated for 2 hours, the residual nitrite contents in treatments 1,3 , and 5 were lower $(p<0.05)$ than that in the control. However, there was no difference $(p>0.05)$ between the residual nitrite contents in treatments 3 and 5, while treatment 1 had a lower $(p<0.05)$ residual nitrite content than treatment 5. However, when the incubation period was increased ( 4 hours), residual nitrite content also increased $(p<$ 0.05 ) in all cases (treatments 2,4 , and 6 ). These results were consistent with previous studies on cooked sausages and hams, which showed that residual nitrite content increased with incubation time $[11,31]$. Thus, our results indicate that sufficient nitrate concentrations in the vegetable powder and ample incubation time for converting nitrate to nitrite are critical for achieving high-quality alternatively cured meat products. Radish powder may be a promising natural source of nitrite/ nitrate, and its addition to alternatively cured products may result in meat products comparable to conventionally cured products and products treated with commercially available celery powder.

The nitrosyl hemochrome content in the products were significantly changed $(p<0.05)$ by the concentration of vegetable powders added and the incubation time (Table 4). When incubated for 2 hours, products treated with $0.15 \%$ radish powder (treatment 1 ) had a lower $(p<0.05)$ nitrosyl hemochrome content than those treated with $0.30 \%$ radish powder (treatment 3 ) or $0.30 \%$ celery powder (treatment 6). Jeong et al. [22] reported a study on ground pork products treated with $0.15 \%, 0.25 \%$, and $0.35 \%$ Chinese cabbage powder or $0.4 \%$ celery juice powder and incubated for 2 hours prior to cooking. They found that the cooked products treated with $0.15 \%$ Chinese cabbage powder had lower nitrosyl hemochrome than the others, which is consistent with our results. Regardless of the type and concentration of vegetable powders used, the nitrosyl hemochrome content of the alternatively cured products (treatments 2,4 , and 6) increased $(p<0.05)$ with incubation time, and reached a level similar $(p>0.05)$ to that in the controls. It has been recognized that incubation time is a key parameter in the production of cured meat treated with vegetablebased ingredients [33]. Therefore, it is possible that the increased amounts of nitrite converted from nitrate by the bacteria during the long incubation periods affect the nitrosyl hemochrome content.

In this study, the total pigment content of the products ranged from 45.73 to $46.58 \mathrm{ppm}$ (Table 4). In a previous study [22], different amounts $(0.15 \%-0.35 \%)$ of Chinese cabbage powder were added to pork products, which resulted in total pigment content ranging from 47.18 to $49.13 \mathrm{ppm}$, similar to our results. However, the total pigment content was not different $(p>0.05)$ between the different vegetable powder treatments and the control, indicating that it was not affected by the types and concentrations of vegetable powders added or the incubation time. These results are also consistent with those of Posthuma et al. [34], who reported that total pigment content did not change in emulsified beef sausages treated with celery juice powder when the incubation time was increased from 5 min to $120 \mathrm{~min}$.

In the cured meat products treated with radish powder, the curing efficiency was significantly increased $(p<0.05)$ when the concentration of the radish powder added was increased from $0.15 \%$ to $0.30 \%$ for both incubation times ( 2 hours, treatments 1 and $3 ; 4$ hours, treatments 2 and 4 ) (Table 4). These results were consistent with those of Choi et al. [6], who found that pork products treated with $0.4 \%$ white kimchi powder showed a higher curing efficiency than those treated with $0.2 \%$ white kimchi powder. Regardless of the types and concentration of vegetable powder added, alternatively cured products incubated for 2 hours had a lower $(p<0.05)$ curing efficiency than the nitrite-treated control. However, the addition of radish powder or celery powder (regardless of the concentration) to the products followed by incubation for 4 hours resulted in an increased curing efficiency $(p<0.05)$. While treatment 2 had a similar curing efficiency to the control, the highest curing efficiency was observed in treatments 4 and 6 . These results suggest that extended incubation 
times could increase the curing efficiency in alternatively cured meat products. In addition, when radish powder was added at low concentrations $(0.15 \%)$ to products, sufficient incubation time would be needed to achieve cured meat characteristics as observed for traditionally cured products.

Alternatively cured products treated with $0.15 \%$ radish powder (treatments 1 and 2) were found to have higher $(p<0.05)$ TBARS values than the control, regardless of the incubation time (Table 4). However, as incubation time increased, the TBARS values in the cured products treated with $0.30 \%$ radish powder or celery powder (treatments $4-6)$ decreased $(p<0.05)$. There were no significant differences $(p>0.05)$ in the TBARS values of these treatments and the control. These results could be attributed to the high residual nitrite and nitrosyl hemochrome contents in this study. Lipid oxidation can be inhibited by the antioxidant properties of nitrite [35]. Similarly, Kim et al. [13] found that pork loins with high residual nitrite content showed low TBARS values.

\section{CONCLUSION}

In this study, the effects of treating alternatively cured meat products with different concentrations of radish powder, followed by different incubation times, on their physicochemical properties were studied by comparing the meat products with sodium nitrite-treated controls or products treated with commercially available celery powder. Regardless of incubation time, treatment with radish powder improved the redness of the alternatively cured products to levels comparable to that of the sodium nitrite-treated controls. Further, treatment with $0.30 \%$ radish power and incubation for 4 hours was effective in improving residual nitrite content, nitrosyl hemochrome content, curing efficiency, and lipid oxidation. Our results indicate that radish powder could make a promising replacement for nitrite/nitrate in meat processing. Further, increased concentrations of radish powder and sufficient incubation time would result in quality characteristics comparable to the products treated with synthetic nitrite or commercially available celery powder. Additionally, in order to facilitate the industrial application of radish powder in alternatively cured meat products, further researches on the sensory properties and microbiological safety during storage should be accompanied.

\section{REFERENCES}

1. Sebranek JG, Bacus JN. Cured meat products without direct addition of nitrate or nitrite: what are the issues? Meat Sci. 2007;77:136-47.https://doi.org/10.1016/j.meatsci.2007.03.025

2. Sindelar JJ, Houser TA. Alternative curing systems. In: Tarté R, editor. Ingredients in meat products: properties, functionality and applications. New York, NY: Springer Science; 2009. p. 379-405.

3. Pegg RB, Shahidi F. Nitrite curing of meat: the N-nitrosamine problem and nitrite alternatives. Hoboken: Wiley-Blackwell; 2004.

4. Alahakoon AU, Jayasena. DD, Ramachandra S, Jo C. Alternatives to nitrite in processed meat: up to date. Trends Food Sci Tech. 2015;45:37-49. https://doi.org/10.1016/j.tifs.2015.05.008

5. Sindelar JJ, Milkowski AL. Sodium nitrite in processed meat and poultry meats: a review of curing and examining the risk/benefit of its use. Champaign, IL: American Meat Science Association; 2011. White paper series No.: 3 .

6. Choi JH, Bae SM, Jeong JY. Effects of the addition levels of white kimchi powder and acerola juice powder on the qualities of indirectly cured meat products. Food Sci Anim Resour. 2020;40:636-48. https://doi.org/10.5851/kosfa.2020.e41

7. Morita H, Sakata R, Nagata Y. Nitric oxide complex of iron (II) myoglobin converted from metmyoglobin by Staphylococcus xylosus. J Food Sci. 1998;63:352-5. https://doi.org/10.1111/ 


\section{j.1365-2621.1998.tb15740.x}

8. Sebranek JG, Jackson-Davis AL, Myers KL, Lavieri NA. Beyond celery and starter culture: advances in natural/organic curing processes in the United States. Meat Sci. 2012;92:267-73. https://doi.org/10.1016/j.meatsci.2012.03.002

9. Shahidi F, Pegg RB. Nitrite-free meat curing systems: update and review. Food Chem. 1992;43:185-91. https://doi.org/10.1016/0308-8146(92)90171-W

10. Sindelar JJ, Cordray JC, Sebranek JG, Love JA, Ahn DU. Effects of varying levels of vegetable juice powder and incubation time on color, residual nitrate and nitrite, pigment, $\mathrm{pH}$, and trained sensory attributes of ready-to-eat uncured ham. J Food Sci. 2007;72:S388-95. https:// doi.org/10.1111/j.1750-3841.2007.00404.x

11. Sindelar JJ, Cordray JC, Sebranek JG, Love JA, Ahn DU. Effects of vegetable juice powder concentration and storage time on some chemical and sensory quality attributes of uncured, emulsified cooked sausages. J Food Sci. 2007;72:S324-32 https://doi.org/10.1111/j.17503841.2007.00369.x

12. Bahadoran Z, Mirmiran P, Jeddi S, Azizi F, Ghasemi A, Hadaegh F. Nitrate and nitrite content of vegetables, fruits, grains, legumes, dairy products, meats and processed meats. J Food Compos Anal. 2016;51:93-105. https://doi.org/10.1016/j.jfca.2016.06.006

13. Kim TK, Yong HI, Jang HW, Lee H, Kim YB, Jeon KH, et al. Quality of sliced cured pork loin with spinach: effect of incubation period with starter culture. J Food Qual. 2019;6373671. https://doi.org/10.1155/2019/6373671

14. Jeong JY, Bae SM, Yoon J, Jeong DH, Gwak SH. Effect of using vegetable powders as nitrite/ nitrate sources on the physicochemical characteristics of cooked pork products. Food Sci Anim Resour. 2020;40:831-43. https://doi.org/10.5851/kosfa.2020.e63.

15. Riel G, Boulaaba A, Popp J, Klein G. Effects of parsley extract powder as an alternative for the direct addition of sodium nitrite in the production of mortadella-type sausage - impact on microbiological, physicochemical and sensory aspects. Meat Sci. 2017;131:166-75. https://doi. org/10.1016/j.meatsci.2017.05.007

16. Shin DM, Hwang KE, Lee CW, Kim TK, Park YS, Han SG. Effect of Swiss Chard (Beta vulgaris var. cicla) as nitrite replacement on color stability and shelf-life of cooked pork patties during refrigerated storage. Korean J Food Sci Anim Resour. 2017;37:418-28. https://doi. org/10.5851/kosfa.2017.37.3.418

17. Chung SY, Kim JS, Kim M, Hong MK, Lee JO, Kim CM, et al. Survey of nitrate and nitrite contents of vegetables grown in Korea. Food Addit Contam. 2003;20:621-8. https://doi. org/10.1080/0265203031000124146

18. Raczuk J, Wadas W, Głozak K. Nitrates and nitrites in selected vegetables purchased at supermarkets in Siedlce, Poland. Rocz Panstw Zakl Hig. 2014;65:15-20.

19. Goyeneche R, Roura S, Ponce A, Vega-Gálvez A, Quispe-Fuentes I, Uribe E, et al. Chemical characterization and antioxidant capacity of red radish (Raphanus sativus L.) leaves and roots. J Funct Foods. 2015;16:256-64. https://doi.org/10.1016/j.jff.2015.04.049

20. Hadley P, Fordham R. Vegetables of temperate climates | swede, turnip, and radish. In: Caballero B, Trugo L, Finglas PM, editors. Encyclopedia of food sciences and nutrition. Cambridge: Academic Press; 2003. p. 5946-8.

21. Terns MJ, Milkowski AL, Claus JR, Sindelar JJ. Investigating the effect of incubation time and starter culture addition level on quality attributes of indirectly cured, emulsified cooked sausages. Meat Sci. 2011;88:454-61. https://doi.org/10.1016/j.meatsci.2011.01.026

22. Jeong JY, Bae SM, Yoon J, Jeong DH, Gwak SH. Investigating the effects of Chinese cabbage powder as an alternative nitrate source on cured color development of ground pork sausages. 
Food Sci Anim Resour. 2020;40:990-1000. https://doi.org/10.5851/kosfa.2020.e69

23. Merino L. Development and validation of a method for determination of residual nitrite/nitrate in foodstuffs and water after zinc reduction. Food Anal Methods. 2009;2:212-20. https:// doi.org/10.1007/s12161-008-9052-1

24. AOAC [Association of Official Analytical Chemists] International. Official methods of analysis of AOAC International. 20th ed. Rockville, MD: AOAC International. 2016.

25. Hornsey HC. The colour of cooked cured pork. I. Estimation of the nitric oxide-haem pigments.J Sci Food Agric. 1956;7:534-40. https://doi.org/10.1002/jsfa.2740070804

26. Tarladgis BG, Watts BM, Younathan MT, Dugan L. A distillation method for the quantitative determination of malonaldehyde in rancid foods. J Am Oil Chem Soc. 1960;37:44-8. https:// doi.org/10.1007/BF02630824

27. Ranasinghe RASN. Marapana RAUJ. Nitrate and nitrite content of vegetables: a review. J Pharmacogn Phytochem. 2018;7:322-8.

28. Sindelar JJ. Investigating uncured no nitrate or nitrite added processed meat products [Ph.D. dissertation]. Ames, IA: Iowa State University; 2006.

29. Banerjee R, Verma AK, Das AK, Rajkumar V, Shewalkar AA, Narkhede HP. Antioxidant effects of broccoli powder extract in goat meat nuggets. Meat Sci. 2012;91:179-84. https://doi. org/10.1016/j.meatsci.2012.01.016

30. Sindelar JJ, Terns MJ, Meyn E, Boles JA. Development of a method to manufacture uncured, no-nitrate/nitrite-added whole muscle jerky. Meat Sci. 2010;86:298-303. https:/doi. org/10.1016/j.meatsci.2010.04.028

31. Krause BL, Sebranek JG, Rust RE, Mendonca A. Incubation of curing brines for the production of ready-to-eat, uncured, no-nitrite-or-nitrate-added, ground, cooked and sliced ham. Meat Sci. 2011;89:507-13. https://doi.org/10.1016/j.meatsci.2011.05.018

32. Holden JM, Eldridge AL, Beecher GR, Buzzard IM, Bhagwat S, Davis CS, et al. Carotenoid content of U.S. foods: an update of the database. J Food Compos Anal. 1999;12:169-96. https://doi.org/10.1006/jfca.1999.0827

33. Sebranek JG, Bacus JN. Natural and organic meat products: regulatory, manufacturing, marketing, quality and safety issues. Champaign, IL: American Meat Science Association; 2007. White paper series No.: 1 .

34. Posthuma JA, Rasmussen FD, Sullivan GA. Effects of nitrite source, reducing compounds, and holding time on cured color development in a cured meat model system. LWT-Food Sci Technol. 2018;95:47-50. https://doi.org/10.1016/j.lwt.2018.04.040

35. Igene JO, Yamauchi K, Pearson AM, Gray JI, Aust SD. Mechanisms by which nitrite inhibits the development of warmed-over flavour (WOF) in cured meat. Food Chem. 1985;18:1-18. https://doi.org/10.1016/0308-8146(85)90099-8 